\title{
Differential expression of $C R K L$ and $A X L$ genes in lung adenocarcinoma subtypes according to the epidermal growth factor receptor and anaplastic lymphoma kinase gene status
}

\author{
DA-PING YU ${ }^{1}$, YU-JIE DONG ${ }^{2}$, HAI-QING ZHANG ${ }^{2}$, JING-HUI WANG $^{3}$, YANG QU $^{2}$, \\ LI-JUAN ZHOU ${ }^{2}$, DAN SU $^{2}$, LI-LI ZHANG ${ }^{2}$, DAN ZHAO $^{2}$ and YI-RAN CAI ${ }^{2}$ \\ Departments of ${ }^{1}$ Thoracic Surgery, ${ }^{2}$ Pathology and ${ }^{3}$ Oncology, Beijing Chest Hospital, \\ Capital Medical University, Beijing 101149, P.R. China
}

Received January 21, 2014; Accepted February 24, 2014

DOI: $10.3892 /$ br.2014.261

\begin{abstract}
Non-small-cell lung cancer (NSCLC) is the most common cause of cancer-related mortality. Adenocarcinoma (AC) is the predominant histological type of NSCLC; however, AC consists of several subtypes. It has not yet been determined whether there is a correlation of CRKL and AXL expression with epidermal growth factor receptor $(E G F R)$ and anaplastic lymphoma kinase $(A L K)$ gene status in lung AC. We assayed exons 18 through 21 of the EGFR gene by direct sequencing; $A L K$ rearrangement and the expression of CRKL and AXL were detected by immunostaining. A total of 212 cases of $\mathrm{AC}$ were included in this study, diagnosed using the novel classification system established by the International Association for the Study of Lung Cancer, the American Thoracic Society and the European Respiratory Society in 2011, including 69 acinar ACs, 17 lepidic predominant ACs (LPAs), 63 papillary, 14 mucinous, 17 micropapillary and 32 solid ACs. Of the 212 cases, 101 harbored EGFR mutations. The most common subtypes carrying delK745-S753 were papillary and acinar ACs. $A L K$ rearrangement was found in 23 cases (11\%) of lung ACs. Acinar and solid ACs were the most frequent subtypes with $A L K$ aberrance, particularly in acinar ACs with cribriform structure (4/5 cases, $80 \%)$. The expression of CRKL was significantly different among the AC subtypes $(\mathrm{P}=0.01)$, with the highest and lowest expression levels of CRKL protein in papillary ACs and LPAs, respectively $(\mathrm{P}<0.05)$. AXL expression was also significantly different among the $\mathrm{AC}$ subtypes $(\mathrm{P}=0.002)$ and was correlated
\end{abstract}

Correspondence to: Dr Yi-Ran Cai, Department of Pathology, Beijing Chest Hospital, Capital Medical University, 97 Ma Chang Street, Tongzhou, Beijing 101149, P.R. China E-mail: cyr7172@gmail.com

Key words: lung adenocarcinoma, epidermal growth factor receptor gene mutation, anaplastic lymphoma kinase gene rearrangement, $C R K L, A X L$ with lymph node infiltration in acinar ACs. ACs with EGFR mutations exhibited high levels of AXL protein expression compared to those without mutations $(\mathrm{P}<0.001)$. Acinar AC with cribriform structure is a distinct subtype that frequently harbors $A L K$ rearrangement. The activation of $A X L$ may be one of the factors contributing to the invasion of acinar and micropapillary ACs.

\section{Introduction}

Lung cancer is the leading cause of cancer-related mortality worldwide $(1,2)$. Adenocarcinoma (AC) is the most common histological subtype of non-small-cell lung cancer (NSCLC) accounting for approximately half of all lung cancers (3). A previous study reported that $>80 \%$ of lung ACs are diagnosed as mixed AC subtype according to the 2004 World Health Organization (WHO) classification (4). Therefore, comprehensive histological profiling is required through semi-quantitative evaluation of the percentages of the various histological components. To address such issues, a new classification based on a multidisciplinary approach to the diagnosis of lung ACs was established by the International Association for the Study of Lung Cancer, the American Thoracic Society and the European Respiratory Society in 2011 (5). In the new nomenclature system, invasive ACs are classified according to the predominant histological pattern into specific subtypes, such as lepidic [formerly the majority of mixed subtype tumors with non-mucinous bronchioloalveolar carcinoma (BAC)], mucinous (formerly mucinous BAC), acinar, papillary, solid and micropapillary ACs. Although widely divergent clinical, radiological, molecular and pathological data have been collected on lung AC, there remains some confusion (5). Despite significant advances regarding the understanding of this type of tumor over the last few decades, there remains a need for universally accepted criteria for the classification of AC subtypes (6,7). As significant resources are invested on trials investigating the molecular and therapeutic aspects of lung $\mathrm{AC}$, the development of standardized criteria is crucial and may lead to improvements in patient care and prognosis. The various subtypes of AC may be associated with a different 
prognosis and the underlying mechanisms have not been clearly determined.

Mutations in exons 18 through 21 of the epidermal growth factor receptor gene $(E G F R)$ are associated with sensitivity to tyrosine kinase inhibitors (TKIs); therefore, it is crucial to elucidate the nature of these mutations. EGFR mutations are mainly classified as 'classical' activating mutations (del19 and L858R) and as variants of unknown function; thus, further analyses are required accordingly (8). Persistent EGFR signaling activation underlies tumor development in human lung ACs. Treatment with gefitinib or erlotinib achieves specific inhibition of the EGFR signaling pathway, leading to apoptosis of cancer cells $(9,10)$.

Echinoderm microtubule-associated protein-like 4 (EML4)-anaplastic lymphoma kinase $(A L K)$, a transforming fusion gene resulting from $A L K$ rearrangement, is a potent oncogenic driver and a promising therapeutic target in ACs via the administration of crizotinib (11-13). The method for the detection of $A L K$ rearrangement includes fluorescent in situ hybridization (FISH), immunohistochemistry (IHC) and reverse transcription-polymerase chain reaction (RT-PCR). FISH is currently the only approved diagnostic test for $A L K$ rearrangement for the detection of break-apart signals. However, there are certain disadvantages to FISH, particularly that apparatuses are not always readily available in routine diagnostic laboratories and subtle intrachromosomal rearrangements may be difficult to interpret $(14,15)$; therefore, false-negative outcomes are inevitable. IHC has been considered as an alternative to FISH, as it is able to detect $A L K$ rearrangements.

It was previously reported that the $C R K L$ is selectively upregulated in a number of malignant tumors, including 49, $55,67,50,50$ and $63 \%$ of breast, lung, skin, ovarian and colon cancers, respectively (16). CRKL is a member of the human Crk adapter protein family and is amplified in lung cancer cells with enhanced expression. In addition, knockdown of $C R K L$ in lung cancer cell lines is associated with a significant decrease in the proliferation, progression, survival, motility and invasiveness of lung cancer cells. These findings suggest that the overexpression of CRKL may contribute to the oncogenic phenotype in lung cancer (17). Although evidence favors $C R K L$ gene amplification in several human malignancies, including lung cancer, the correlation between $C R K L$ and EGFR and the clinicopathological characteristics in lung ACs has not been clearly determined.

$A X L$, a receptor tyrosine kinase, is associated with the development of several tumors. Elevated AXL expression and interaction with its ligand, growth arrest-specific 6 (Gas6), have been associated with cell survival, proliferation and migration in solid tumors $(18,19)$. AXL was shown to be increasingly upregulated during multistep esophageal carcinogenesis and is an adverse prognostic marker in esophageal AC (20). A recent study identified $A X L$ activation as a novel mechanism of acquired resistance to EGFR inhibitors in NSCLC (21). The overexpression of AXL is consistently manifested in prostate cancer cell lines and human prostate tumors, whereas blockade of AXL expression strongly inhibits proliferation, migration, invasion and tumor growth (22).

The primary aim of this study was to analyze the original expression levels of CRKL and AXL proteins prior to TKI therapy and determine the correlation of CRKL and AXL expression with the status of $A L K$ and EGFR among the different histological subtypes of lung AC. We hypothesized that the characteristics of CRKL and AXL expression are correlated with multiple clinicopathological factors. Owing to the presence of lung AC subtypes and targeted therapy with gefitinib and crizotinib, it is crucial to evaluate the expression of CRKL and AXL in ACs by different EGFR and ALK status.

\section{Materials and methods}

Tumor samples. A total of 212 primary lung AC samples from patients who had undergone surgery at the Beijing Chest Hospital (Beijing, China) between 2006 and 2012 were analyzed. All the sections were reviewed by 2 reference pathologists (Yi-Ran Cai and Yu-Jie Dong) to confirm the diagnosis and predominance $(>70 \%)$ of tumor tissues. The ACs were reviewed following the new classification (5) and the 2 observers were blinded to the outcomes. The clinicopathological characteristics, including age, gender and histological subtype were recorded.

DNA extraction, PCR amplification and direct sequencing for EGFR mutations. Genomic DNA was extracted from 50-100 mg tumor tissue scraped off formalin-fixed and paraffin-embedded blocks according to the previously described protocol (23). Briefly, PCR for exons 18 through 21 was performed with $100 \mathrm{ng}$ template DNA in a 50- $\mu 1$ volume containing 0.75 U HotStarTaq DNA polymerase (Fermentas International Inc., Ontario, Canada), $5 \mu \mathrm{l} \mathrm{PCR}$ buffer, $0.8 \mu \mathrm{M}$ deoxyribonucleotide triphosphate, $0.5 \mu \mathrm{M}$ of each primer and different concentrations of $\mathrm{MgCl}_{2}$, depending on the various markers. The nucleic acid used for mutations was based on NM_005228.3. The primers were designed as follows: exon 18, forward 5'-CAACCAAGCTCTCTTGAGGATC-3' and reverse 5'-CCCAGCCCAGAGGCCTGT-3'; exon 19, forward 5'-GCA GCATGTGGCACCATCTC-3' and reverse 5'-AGAGCCATG GACCCCCACAC-3'; exon 20, forward 5'-CACACTGAC GTGCCTCTCC-3' and reverse 5'-AGCAGGTACTGGGAG CCAAT-3'; and exon 21, forward 5'-TCTGTCCCTCACAGC AGGGTCT-3' and reverse 5'-GCTGGCTGACCTAAAGCC ACC-3'. Amplification and sequencing of the exon fragments were performed as previously described (23). The PCR products were sequenced in the sense and antisense directions. Only specimens with an identified mutation in both rounds were recorded as mutation-positive.

Construction of tissue microarrays (TMAs). In cases with varied histological patterns, the most representative area was selected for TMA construction. Three cores $(2 \mathrm{~mm}$ in diameter) from each patient were drilled out of individual paraffin-embedded blocks (donor blocks) and placed into new recipient TMA paraffin blocks (24). Serial sections were cut and IHC was performed.

IHC for the CRKL and AXL genes and ALK rearrangement. Tissue sections $(4 \mu \mathrm{m})$ prepared from TMA blocks were deparaffinized using xylene and rehydrated through an ethanol series to water. The slides were incubated with rabbit anti-CRKL (ab151791; Abcam, Cambridge, UK) and goat anti-AXL 

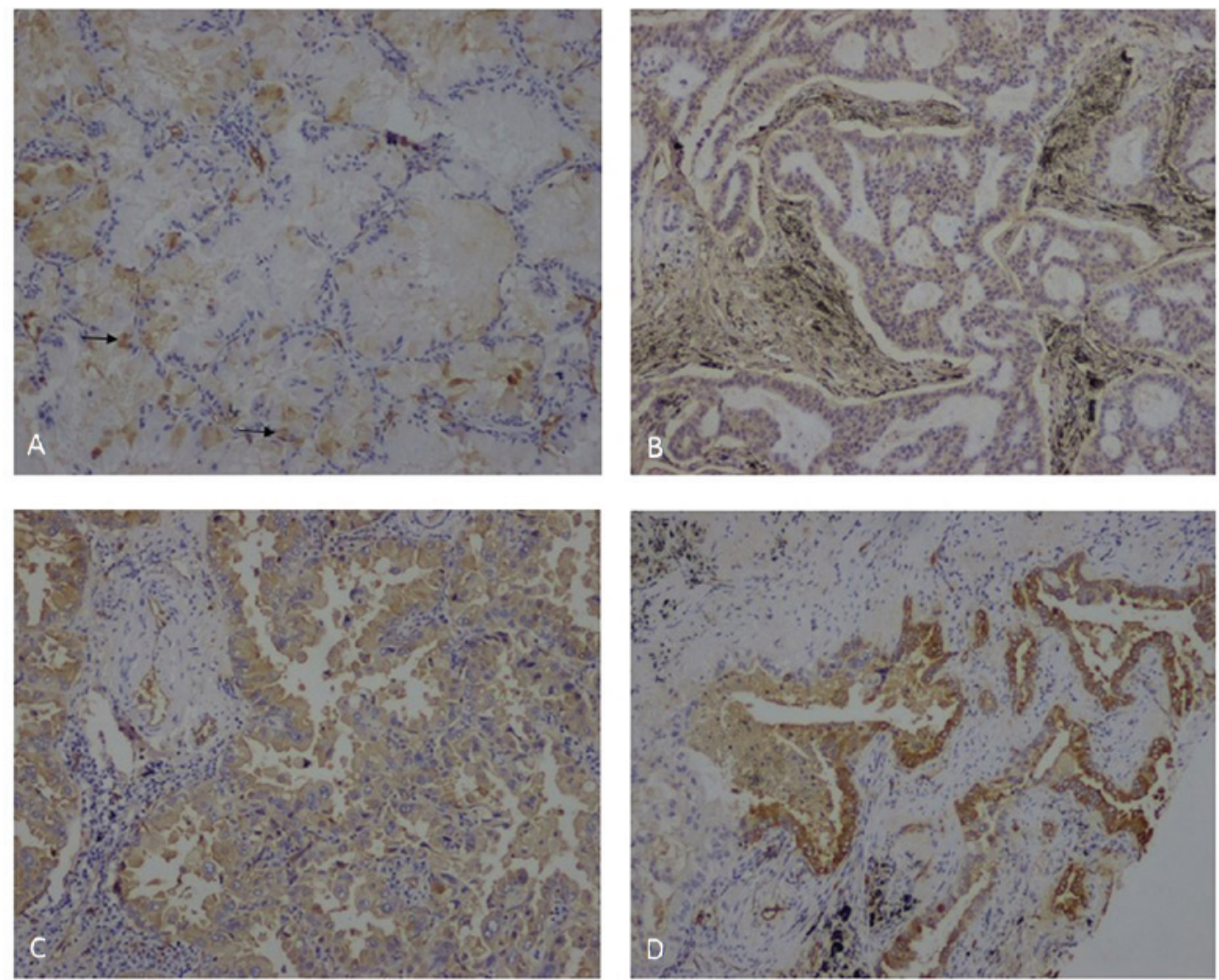

Figure 1. Immunohistochemical staining of lung AC samples (magnification, x100). The antibodies against AXL and CRKL exhibited weak cytoplasmic staining in (A) mucinous AC (except for sparse cells with moderate staining, black arrows) and (B) acinar AC. (C and D) The antibody against AXL exhibited moderately and strongly positive staining in (C) papillary and (D) acinar AC. AC, adenocarcinoma.
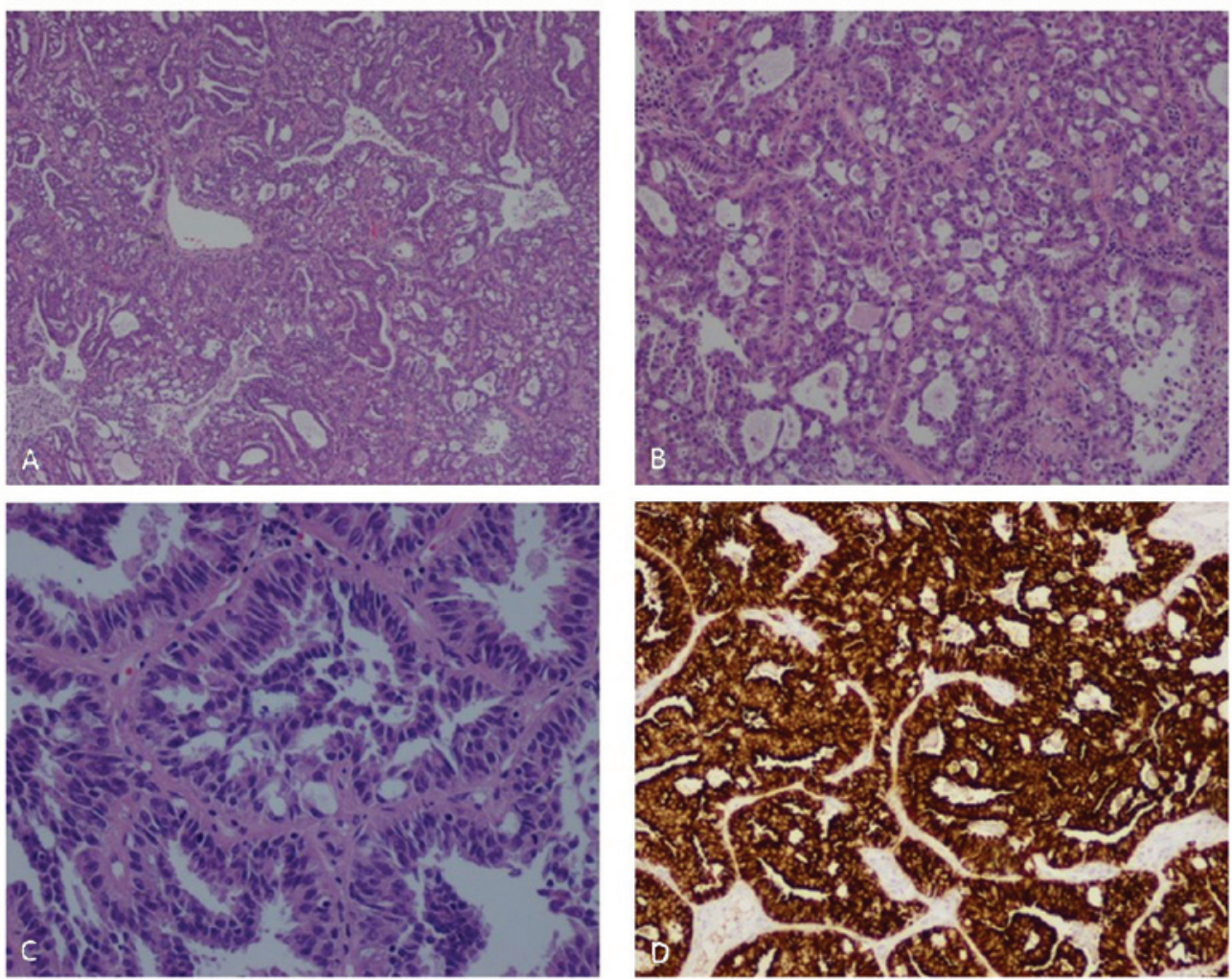

Figure 2. Representative acinar AC with cribriform structure and immunohistochemical staining for anaplastic lymphoma kinase gene $(A L K)$ rearrangement. (A) Acinar structure with cribriform pattern under low-power magnification. Tumor parenchyma crowded with glands and pseudolumina (hematoxylin and eosin; magnification, $\mathrm{x} 40$ ). (B) Cribriform appearance and predominant pseudolumina constitute the tumor parenchyma (hematoxylin and eosin; magnification, x100). (C) Gland surrounded by columnar tumor cells and pseudolumina formed in the gland (hematoxylin and eosin; magnification, x200). (D) $A L K$ rearrangement shown by positive Ventana anti-ALK staining, represented by brown cytoplasmic granules (magnification, x200). AC, adenocarcinoma. 
Table I. Non-parametric test (Kruskal-Wallis test) for the correlation of CRKL and AXL staining scores with the pathological characteristics of lung ACs.

\begin{tabular}{|c|c|c|c|c|}
\hline \multirow[b]{2}{*}{ Characteristics } & \multicolumn{4}{|c|}{$\begin{array}{l}\text { Wilcoxon scores } \\
\text { (average score) }\end{array}$} \\
\hline & CRKL & $\mathrm{P}$ & AXL & $\mathrm{P}$ \\
\hline Gender & & 0.56 & & 0.52 \\
\hline Male $(n=118)$ & 104 & & 104 & \\
\hline Female $(n=94)$ & 109 & & 110 & \\
\hline AC subtypes & & 0.01 & & 0.002 \\
\hline Acinar $(n=69)$ & 109 & & 116 & \\
\hline Lepidic predominant $(\mathrm{n}=17)$ & 71 & & 58 & \\
\hline Micropapillary (n=17) & 99 & & 112 & \\
\hline Papillary (n=63) & 125 & & 119 & \\
\hline Solid $(n=32)$ & 98 & & 96 & \\
\hline Mucinous (n=14) & 79 & & 79 & \\
\hline$E G F R$ status $^{\mathrm{a}}$ & & 0.39 & & $<0.001$ \\
\hline Mutation $(\mathrm{n}=101)$ & 107 & & 119 & \\
\hline Non-mutation $(n=104)$ & 99 & & 88 & \\
\hline$A L K$ status $^{\mathrm{b}}$ & & 0.56 & & 0.43 \\
\hline Fusion gene $(n=23)$ & 112 & & 96 & \\
\hline Non-fusion gene $(n=186)$ & 104 & & 106 & \\
\hline Smoking status & & 0.08 & & 0.75 \\
\hline Non-smoker (n=128) & 112 & & 108 & \\
\hline Smoker $(n=84)$ & 97 & & 105 & \\
\hline Clinical stage & & 0.28 & & 0.53 \\
\hline $\mathrm{I}(\mathrm{n}=73)$ & 115 & & 106 & \\
\hline II $(\mathrm{n}=19)$ & 87 & & 108 & \\
\hline IIIA $(n=72)$ & 108 & & 113 & \\
\hline IIIB+IV (n=48) & 100 & & 96 & \\
\hline
\end{tabular}

a205 cases were successfully screened. ${ }^{\text {b209 }}$ cases were successfully screened. $E G F R$, epidermal growth factor receptor gene; $A L K$, anaplastic lymphoma kinase gene; AC, adenocarcinoma; P, P-value.

(AF154; R\&D Systems, Minneapolis, MN, USA) polyclonal antibodies, using a modification of the avidin-biotin-peroxidase method provided by the manufacturer. The slides were incubated with the primary antibody overnight at $4^{\circ} \mathrm{C}$ and at a 1:200 dilution. MaxVision ${ }^{\mathrm{TM}}$ HRP-Polymer system (kit 5030 and 5108; Maixin Bio, Fuzhou, China) was used for immunohistochemical analysis following the manufacturer's instructions. Detection was accomplished using 3,3'-diaminobenzidine staining (DAB; ImmunoCruz ${ }^{\mathrm{TM}}$ staining system; Santa Cruz Biotechnology, Inc., Santa Cruz, CA, USA). Subsequently, the slides were counterstained with hematoxylin and the stained tumor cells $(\geq 1,000$ cells) were scored by 2 independent observers (Yi-Ran Cai and Yu-Jie Dong). Cytoplasmic staining was considered positive for CRKL and AXL. The immunoreactivity of carcinoma samples was semi-quantitatively evaluated via 2 aspects, the percentage of positive cells and staining intensity, which was scored as follows: 0 , no staining; 1, light-yellow staining; 2 , yellow staining; and 3, brown staining. The final scores, ranging from 0 to 300 , were the product of the percentage and staining intensity of the positive cells for statistical analysis (Fig. 1).

IHC analysis for $A L K$ rearrangement was performed using the Ventana method on a BenchMark XT ${ }^{\mathrm{TM}}$ autostainer (Ventana Medical Systems, Inc., Tucson, AZ, USA) with a ready-to-use primary anti-ALK rabbit monoclonal antibody (D5F3; Ventana Medical Systems, Inc.). The staining procedure followed the Ventana $A L K$ test protocol using an OptiView Amplification kit and an OptiView DAB IHC detection kit (Ventana Medical Systems, Inc.). The presence or absence of $A L K$ rearrangement was evaluated by adopting a binary judgment system following the manufacturer's protocol. Neoplastic cells with diffuse brown cytoplasmic staining were defined as $A L K$ rearrangement-positive, otherwise cells were defined as negative (Fig. 2D).

Statistical analysis. Non-parametric analysis of variance (ANOVA) was used to analyze the non-normal distribution data of CRKL and AXL expression. The correlation of CRKL and AXL expression with the clinicopathological characteristics were analyzed by the cross tabulation $\chi^{2}$ test or Fisher's exact test. The mutual correlation between the expression of CRKL and AXL was assayed by Spearman's rho. Factorial ANOVA was used for mutual comparisons to evaluate the expression of CRKL and AXL in different AC subtypes. All the statistical tests were two-sided and $\mathrm{P}=0.05$ was considered to indicate a statistically significant difference. All the statistical analyses were performed on a SAS system, version 9.2 (SAS Institute, Inc., Cary, NC, USA) for Windows.

\section{Results}

Patient and histopathological characteristics. The clinicopathological characteristics are listed in Table I. Of the 212 patients with lung ACs, 118 were men (55.7\%). The median age was 63 years (range, 32-79 years) and 55 years (range, 23-74 years) in the male and female patients, respectively. All the samples were diagnosed as invasive AC and classified into 6 subtypes as follows: 69 acinar ACs (32.5\%), 17 lepidic predominant ACs (LPAs) (8\%), 63 papillary (29.7\%), 14 mucinous (6.6\%), 17 micropapillary (8\%) and 32 solid ACs (15.1\%). Of the 212 cases, $128(60.4 \%)$ had no history of smoking and 113 ACs (53.3\%) had positive local lymph nodes. A total of 92 cases $(43.4 \%)$ were diagnosed with early-stage lung cancer (stages I and II), 72 (34\%) were diagnosed at stage IIIA and $48(22.6 \%)$ were diagnosed with late-stage lung cancer (stages IIIB and IV).

EGFR mutation and ALK rearrangement in lung ACs. Mutations of the EGFR kinase domain (exons 18 through 21) were successfully screened in 205 lung ACs and a total of 101 cases (49.3\%) were found to harbor $E G F R$ mutations (Table I). The distribution of EGFR mutations were as follows: G719A/S was present in 3 acinar (42.9\%) and 4 papillary ACs (57.1\%); delK745-S753 was identified in 13 acinar ACs (24.4\%), 3 LPAs (5.7\%), 4 micropapillary (7.6\%), 2 mucinous (3.8\%), 26 papillary (49.1\%) and 5 solid ACs (9.4\%); and L858R was identified in 14 acinar (37.8\%), 3 LPAs (8.1\%), 3 micropapillary (8.1\%), 11 papillary (29.8\%) and 6 solid ACs (16.2\%). 
Table II. Correlation of CRKL and AXL expression with $A L K$ status in lung ACs.

\begin{tabular}{|c|c|c|c|c|c|c|c|c|}
\hline \multirow[b]{2}{*}{$\begin{array}{l}\text { AC } \\
\text { subtypes }\end{array}$} & \multicolumn{4}{|c|}{ Median staining score of CRKL } & \multicolumn{4}{|c|}{ Median staining score of AXL } \\
\hline & $\begin{array}{c}A L K \\
\text { rearrangement } \\
(\text { mean } \pm \mathrm{SD})\end{array}$ & $\mathrm{P}<0.05$ & $\begin{array}{l}A L K \text { without } \\
\text { rearrangement } \\
\text { (mean } \pm \mathrm{SD})\end{array}$ & $\mathrm{P}<0.05$ & $\begin{array}{c}A L K \\
\text { rearrangement } \\
(\text { mean } \pm \mathrm{SD})\end{array}$ & $\mathrm{P}<0.05$ & $\begin{array}{l}A L K \text { without } \\
\text { rearrangement } \\
(\text { mean } \pm \mathrm{SD})\end{array}$ & $\mathrm{P}<0.05$ \\
\hline $\begin{array}{l}\text { Acinar } \\
(\mathrm{N} 1=58, \mathrm{~N} 2=8)\end{array}$ & $\begin{array}{c}151 \\
(154 \pm 35.6)\end{array}$ & a & $\begin{array}{c}124 \\
(131.3 \pm 45.5)\end{array}$ & vs. LPA & $\begin{array}{c}101 \\
(98 \pm 37)\end{array}$ & & $\begin{array}{c}101 \\
(107.5 \pm 49.4)\end{array}$ & $\mathrm{b}$ \\
\hline $\begin{array}{l}\mathrm{LPA} \\
(\mathrm{N} 1=17, \mathrm{~N} 2=0)\end{array}$ & $\mathrm{N} / \mathrm{A}$ & & $\begin{array}{c}100 \\
(97 \pm 59.3)\end{array}$ & & $\mathrm{N} / \mathrm{A}$ & & $\begin{array}{c}50 \\
(55.3 \pm 51.4)\end{array}$ & \\
\hline $\begin{array}{l}\text { Micropapillary } \\
(\mathrm{N} 1=13, \mathrm{~N} 2=4)\end{array}$ & $\begin{array}{c}171.7 \\
(166 \pm 53.3)\end{array}$ & a & $\begin{array}{c}100 \\
(116 \pm 32)\end{array}$ & & $\begin{array}{c}109 \\
(94 \pm 72)\end{array}$ & & $\begin{array}{c}107 \\
(103 \pm 49)\end{array}$ & $\mathrm{b}$ \\
\hline $\begin{array}{l}\text { Papillary } \\
(\mathrm{N} 1=62, \mathrm{~N} 2=1)\end{array}$ & $130(130)$ & & $\begin{array}{c}145 \\
(141 \pm 45.5)\end{array}$ & Vs. LPA & $\begin{array}{c}100 \\
(100)\end{array}$ & & $\begin{array}{c}112 \\
(110 \pm 56.3)\end{array}$ & $\mathrm{b}$ \\
\hline $\begin{array}{l}\text { Solid } \\
(\mathrm{N} 1=26, \mathrm{~N} 2=6)\end{array}$ & $\begin{array}{c}121.7 \\
(129 \pm 41.3)\end{array}$ & a & $\begin{array}{c}118 \\
(119 \pm 40)\end{array}$ & $\begin{array}{c}\text { vs. papillary } \\
\text { AC }\end{array}$ & $\begin{array}{c}88 \\
(87.5 \pm 14.7)\end{array}$ & & $\begin{array}{c}92 \\
(94 \pm 62)\end{array}$ & $\mathrm{b}$ \\
\hline $\begin{array}{l}\text { Mucinous } \\
(\mathrm{N} 1=10, \mathrm{~N} 2=4)\end{array}$ & $\begin{array}{c}77.5 \\
(73 \pm 27.1)\end{array}$ & & $\begin{array}{c}125 \\
(124 \pm 30)\end{array}$ & & $\begin{array}{c}81.7 \\
(100 \pm 56.7)\end{array}$ & & $\begin{array}{c}85 \\
(76 \pm 34)\end{array}$ & \\
\hline
\end{tabular}

${ }^{\mathrm{a}}$ Compared to mucinous AC; ${ }^{\mathrm{b}}$ compared to LPA. N1, number of corresponding subtypes without $A L K$ rearrangement; N2, number of corresponding subtypes with $A L K$ rearrangement; AC, adenocarcinoma; $A L K$, anaplastic lymphoma kinase gene; LPA, lepidic predominant AC; N/A, not available; SD, standard deviation.
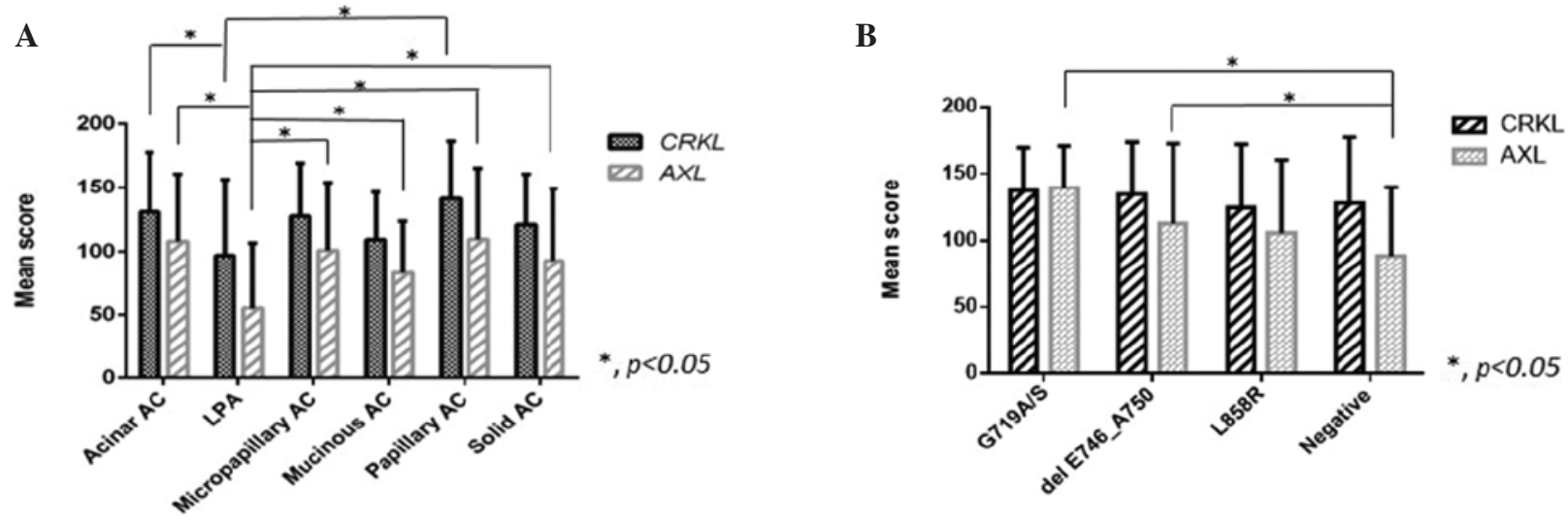

Figure 3. Expression of CRKL and AXL in various histological subtypes and by different EGFR status. (A) The average scores of CRKL and AXL were compared among the AC subtypes. The expression of CRKL in LPAs was lower compared to that in acinar and papillary ACs (P<0.05); similarly, the expression of AXL was lower in LPAs compared to that in the other histological subtypes $(\mathrm{P}<0.05)$. (B) Higher levels of AXL expression were detected in ACs with G719A/S and delE746-A750 mutations compared to ACs without EGFR mutations. There was no significant difference in the expression of CRKL when stratified by different EGFR status. ${ }^{*} \mathrm{P}<0.05$. AC, adenocarcinoma; LPAs, lepidic predominant ACs.

Composite mutations were detected in 2 cases: 1 case was papillary AC with G719S and S768I mutations; and the other case was acinar AC with delE746-A750 and L858R mutations. The most frequent mutations were nucleotide deletions in the K745-S753 region of exon 19 (54.1\%) and point mutations of L858R in exon 21 (37\%). G719A or G719S mutations were found in 7 cases $(6.9 \%)$. No T790M mutation in exon 20 was detected in our cohort.

$A L K$ rearrangement was analyzed by Ventana IHC. A total of $23 \mathrm{ACs}(11 \%)$ exhibited $A L K$ translocation, which was increased to $22.1 \%$ in the subgroup without EGFR mutations.
The ACs exhibiting $A L K$ rearrangement included 8 acinar (34.8\%), 4 micropapillary (17.4\%), 4 mucinous (17.4\%), 1 papillary (4.4\%) and 6 solid ACs (26.1\%). There were no LPAs with $A L K$ rearrangement. Notably, 4 out of 5 ACs with cribriform structure among acinar ACs were found to be positive for $A L K$ rearrangement (Fig. 2). No tumor was found harboring both EGFR mutation and $A L K$ rearrangement.

Expression of CRKL and AXL in lung ACs and association with EGFR and ALK status. The staining scores of CRKL and AXL were compared by non-parametric ANOVA. The 
Table III. Mutual comparisons of CRKL and AXL expression with EGFR status among lung AC subtypes.

Median staining score of CRKL

Median staining score of AXL

\begin{tabular}{|c|c|c|c|c|c|c|c|c|}
\hline $\begin{array}{l}\text { AC } \\
\text { subtypes }\end{array}$ & $\begin{array}{c}E G F R \\
\text { mutation } \\
(\text { mean } \pm \mathrm{SD})\end{array}$ & $\mathrm{P}<0.05$ & $\begin{array}{c}E G F R \\
\text { non-mutation } \\
(\text { mean } \pm \mathrm{SD})\end{array}$ & $\mathrm{P}<0.05$ & $\begin{array}{c}E G F R \\
\text { mutation } \\
(\text { mean } \pm \mathrm{SD})\end{array}$ & $\mathrm{P}<0.05$ & $\begin{array}{c}E G F R \\
\text { non-mutation } \\
(\text { mean } \pm \mathrm{SD})\end{array}$ & $\mathrm{P}<0.05$ \\
\hline $\begin{array}{l}\text { Acinar } \\
(\mathrm{N} 1=33, \mathrm{~N} 2=32)\end{array}$ & $\begin{array}{c}122.9 \\
(130.4 \pm 34.7)\end{array}$ & & $\begin{array}{c}131.7 \\
(138.9 \pm 53)\end{array}$ & $\mathrm{b}$ & $\begin{array}{c}115.8 \\
(120.9 \pm 51.7)\end{array}$ & & $\begin{array}{c}100 \\
(102.5 \pm 48.4)\end{array}$ & \\
\hline $\begin{array}{l}\mathrm{LPA} \\
(\mathrm{N} 1=10, \mathrm{~N} 2=6)\end{array}$ & $\begin{array}{c}95 \\
(99.7 \pm 75.3)\end{array}$ & $\mathrm{a}$ & $\begin{array}{c}101.7 \\
(100.3 \pm 52.9)\end{array}$ & $\mathrm{a}$ & $\begin{array}{c}31.7 \\
(53.2 \pm 67.2)\end{array}$ & $\mathrm{a}, \mathrm{d}, \mathrm{e}$ & $\begin{array}{c}41.7 \\
(54 \pm 46)\end{array}$ & $\mathrm{a}, \mathrm{d}$ \\
\hline $\begin{array}{l}\text { Micropapillary } \\
(\mathrm{N} 1=10, \mathrm{~N} 2=7)\end{array}$ & $\begin{array}{c}100 \\
(133.3 \pm 46.2)\end{array}$ & & $\begin{array}{c}110 \\
(123.8 \pm 41)\end{array}$ & & $\begin{array}{c}141.7 \\
(127.6 \pm 22.6)\end{array}$ & & $\begin{array}{c}80 \\
(82.3 \pm 61)\end{array}$ & \\
\hline $\begin{array}{l}\text { Papillary } \\
(\mathrm{N} 1=18, \mathrm{~N} 2=43)\end{array}$ & 140 & & 151 & $\mathrm{c}$ & $\begin{array}{c}116.7 \\
(114.5 \pm 54.9)\end{array}$ & & $\begin{array}{c}98.3 \\
(98.2 \pm 60.1)\end{array}$ & \\
\hline $\begin{array}{l}\text { Solid } \\
(\mathrm{N} 1=21, \mathrm{~N} 2=11)\end{array}$ & 120 & & 115 & & $\begin{array}{c}106.7 \\
(108.8 \pm 75.4)\end{array}$ & & $\begin{array}{c}83.3 \\
(84.8 \pm 42.8)\end{array}$ & \\
\hline $\begin{array}{l}\text { Mucinous } \\
(\mathrm{N} 1=12, \mathrm{~N} 2=2)\end{array}$ & 125 & & 100 & & $\begin{array}{c}97.5 \\
(97.5 \pm 17.7)\end{array}$ & & $\begin{array}{c}84.2 \\
(80.3 \pm 43.6)\end{array}$ & \\
\hline
\end{tabular}

${ }^{\mathrm{a} C}$ Compared to papillary AC; ${ }^{\mathrm{b}}$ compared to LPA; ${ }^{\mathrm{c}}$ compared to mucinous AC; ${ }^{\mathrm{d}}$ compared to acinar AC; ${ }^{\mathrm{e}}$ compared to micropapillary AC. N1, number of corresponding subtypes without EGFR non-mutation; N2, number of corresponding subtypes with EGFR mutation; AC, adenocarcinoma; EGFR, epidermal growth factor receptor gene; LPA, lepidic predominant AC; SD, standard deviation.

average Wilcoxon scores were used to compare the staining scores of CRKL and AXL with the clinicopathological characteristics (Table I). No statistical difference was observed between CRKL expression and clinical parameters, such as gender $(\mathrm{P}=0.56)$, smoking status $(\mathrm{P}=0.08)$, clinical stage $(\mathrm{P}=0.28), E G F R$ status $(\mathrm{P}=0.39)$ and $A L K$ status $(\mathrm{P}=0.56)$. CRKL and AXL were expressed at different levels among the $\mathrm{AC}$ subtypes $(\mathrm{P}=0.01$ and $\mathrm{P}=0.002$, respectively). The $\mathrm{AC}$ types with the highest and lowest CRKL expression levels were papillary ACs $(141 \pm 45.5)$ and LPAs $(97 \pm 59.3)$, respectively. Mutual comparisons were used to disclose the differences among histological subtypes (Fig. 2). The expression level of CRKL in LPAs was significantly lower compared to that in acinar and papillary ACs. Papillary ACs exhibited a higher CRKL expression compared to solid, mucinous ACs and LPAs $(\mathrm{P}<0.05)$. Furthermore, papillary ACs expressed the highest level of CRKL, regardless of the EGFR status. AXL expression in LPAs was significantly lower compared to that in any of the other 4 subtypes $(\mathrm{P}<0.05)$ (Fig. 3A). The expression level of AXL was higher only in acinar ACs with lymph node invasion, compared to that in $\mathrm{AC}$ subtypes without metastasis (33.5 vs. 22.9; $\mathrm{P}=0.02$ ).

The levels of CRKL and AXL expression were also analyzed among AC subtypes stratified by EGFR and $A L K$ status (Tables II and III). ACs with the EGFR wild-type expressed the lowest level of AXL compared to those with G719A/S and delE746_A750 mutations (Fig. 3B). The AXL expression levels were higher among ACs with EGFR mutations compared to those without mutations $(\mathrm{P}<0.001)$. Among the ACs with $A L K$ rearrangement, mucinous and micropapillary ACs exhibited the lowest and highest levels of CRKL expression, respectively; however, there was no difference in AXL expression. A positive correlation between CRKL and AXL expression was detected among the 11 solid ACs with EGFR mutations ( $\mathrm{r}=0.73 ; \mathrm{P}=0.01)$. In addition, we observed a significant difference in $A X L$ expression among the AC subtypes; a lower $A X L$ expression was found in LPAs compared to that in acinar, micropapillary, papillary and solid ACs $(\mathrm{P}<0.05)$, whereas LPAs exhibited the lowest expression level of $C R K L$ and $A X L$ compared to the other subtypes (Fig. 2). Among the ACs with $A L K$ translocation, mucinous ACs exhibited a significantly lower $C R K L$ level $(73 \pm 27.1)$ compared to acinar, micropapillary and solid ACs $(\mathrm{P}<0.05)$.

\section{Discussion}

Approximately $80 \%$ of lung ACs are classified as mixed subtype, according to the 2004 WHO classification system; however, it has been proposed that a semi-quantitative assessment of the percentage of the various histological components of ACs, including acinar, papillary, micropapillary, lepidic and solid ACs, may enable the classification of tumors according to their predominant histological subtype (25). As 70-90\% of the surgically resected lung tumors are diagnosed as invasive ACs, it is crucial to adopt a practical method to address tumors that comprise a complex heterogeneous mixture of histological subtypes. Over the last few years, multiple independent research groups have intentionally classified lung ACs according to the predominant subtypes (25-29). Prominent heterogeneous structures in ACs have attracted increasing attention from pathologists following the establishment of the new classification system. The present study was commenced once the tissue sections were reviewed and diagnosed based on the new classification system. We observed that, in the 
2004 WHO classification, the majority of the LPAs were merged among a heterogeneous group of tumors that included predominantly invasive ACs. However, LPA, according to the new classification, is defined as a non-mucinous AC with its predominant component exhibiting lepidic growth along the surface of the alveolar walls; thus, LPA is now independent from invasive mucinous AC. Acinar predominant AC exhibits a predominant glandular component (6). Cribriform arrangements are considered to be a pattern of acinar AC (30). Papillary predominant AC includes a major component of glandular cells spreading along central fibrovascular cores. Solid predominant AC exhibits recognizable patterns lacking acinar, papillary, micropapillary or lepidic growth and intracellular mucin. Micropapillary AC, a new subtype, exhibits tumor cells growing in papillary tufts, which lack fibrovascular cores (31). Micropapillary ACs were previously reported in patients with early-stage lung cancer with a poor prognosis $(27,32)$ and their poor prognosis is similar to that of ACs with a predominant solid subtype (33).

Recent studies reported that the overexpression or amplification of $C R K L$ and the activation of $A X L$ are associated with resistance to TKIs $(9,11,21,34)$. However, the number of available studies on the correlation between the expression of these biomarkers and the histological subtypes is currently limited. The correlation of CRKL and AXL expression with the $E G F R$ or $A L K$ status remains to be elucidated when stratified by histological subtype. The highest frequency of EGFR mutations is found in the Asian population, non-smokers and individuals with non-mucinous tumors (35). These mutations are point mutations in exons 18 (G719A/C), 20 (T790M), 21 (L858R and L861Q) and an in-frame deletion in exon 19 from codon 746-750 (E746-A750 deletion) (9,36). The most common mutations are L858R and in-frame deletions in exon 19. In the present study, 101 ACs (49.3\%) were found to harbor EGFR mutations and $>90 \%$ of the EGFR mutations were L858R and delE746_A750. These findings were consistent with several studies that investigated the prevalence and specificity of EGFR alterations in lung ACs. The EGFR mutation status was shown to be significantly associated with LPA, papillary and micropapillary AC subtypes (5). Previous clinical outcomes suggest that accurate histological subtyping and EGFR mutation testing are crucial and should be included to guide the initial therapy algorithm for lung AC. A total of 54.1 and $37 \%$ of mutant ACs in this study were found to harbor delK745-S753 and L858R mutations, respectively. The most common subtypes carrying exon 19 in-frame deletions were papillary (49.1\%) and acinar ACs (24.4\%). It was previously reported that EGFR delE746_A750 and L858R mutants confer ligand-independent activation and prolonged receptor kinase activity following ligand stimulation. The activity of the L858R mutant was shown to be 20 -fold higher compared to that of the wild-type kinase domain (37). In our study, histological subtypes with L858R exhibited relatively lower expression levels of CRKL and AXL compared to other mutations. Papillary ACs expressed CRKL to the highest level, regardless of the EGFR status, suggesting that the activation of CRKL is more common in papillary ACs in comparison to other histological subtypes. Within the histological groups harboring EGFR mutations, the highest expression of AXL was observed in micropapillary ACs, suggesting that the activation of $A X L$ is one of the factors associated with the poor prognosis of this histological entity.

$A L K$ rearrangement results in a fusion gene, $E M L 4-A L K$, which is located on chromosome $2 \mathrm{p}$ and is formed by a chromosomal inversion. This fusion gene defines a distinct molecular subset of ACs, which benefits from treatment with $A L K$-inhibitors. Robust and reliable laboratory tests for predictive biomarkers are critical in order to select appropriate patients for targeted therapy. IHC using specific antibodies corresponds well to $E M L 4-A L K$ translocation and may be a useful screening method $(14,15,38,39)$. IHC has been considered an alternative to FISH. In our cohort, 23 ACs (11\%) were positive for $A L K$ rearrangement and $22.1 \%$ of these ACs did not harbor an $E G F R$ mutation. The incidence of $A L K$ rearrangement was markedly increased in our cases compared to that reported in young men and light or non-smokers $(5 \%)$ in Western countries $(14,40,41)$. A total of 13 men $(56.5 \%)$ and 15 light or non-smokers $(65.2 \%)$ were found to be $E M L 4-A L K$ positive. The histological subtypes with $A L K$ translocation included 8 acinar $(34.8 \%), 4$ micropapillary (17.4\%), 4 mucinous (17.4\%), 1 papillary (4.4\%) and 6 solid ACs (26.1\%). A variety of histological characteristics are associated with $E M L 4-A L K$ rearrangement, including acinar, papillary, cribriform and signet-ring patterns, as well as intraand extracytoplasmic mucin production $(14,40,41)$. Notably, in our study, 4 of the 5 ACs with cribriform structure were $A L K$ rearrangement-positive (Fig. 1), suggesting that ACs with such architecture may be associated with a higher ratio of $A L K$ translocation.

The amplification of $C R K L$ has been implicated in various types of human cancers and its expression is associated with enhanced cancer cell proliferation and invasion $(16,17)$. However, CRKL protein expression and its correlation with clinicopathological factors has not yet been elucidated in ACs. In our study, CRKL protein levels were not found to be significantly correlated with clinical characteristics, such as gender, smoking history, clinical stage, EGFR and $A L K$ status. However, the expression of CRKL was significantly different among the AC subtypes. Papillary ACs and LPAs conferred the highest and lowest levels of CRKL protein, respectively (Table I). CRKL activation was significantly lower in LPAs compared to that in acinar and papillary ACs. Among the histological subtypes with $A L K$ translocation, mucinous ACs exhibited a lower expression level of CRKL, in contrast to acinar, micropapillary and solid ACs.

$A X L$ is a member of the Tyro3, $A X L$ and Mertk subfamily $(42,43)$. Activation of $A X L$ protects cells against apoptosis and increases migration, aggregation and growth via multiple downstream pathways. Upregulation of the Gas6/AXL pathway is more evident under pathological compared to normal physiological conditions. EGFR-mutant lung cancer models in vitro and in vivo exhibited increased activation of $A X L$ with acquired resistance to erlotinib without T790M alteration, suggesting that $A X L$ may be a promising therapeutic target whose inhibition may prevent or overcome acquired resistance to EGFR TKIs in individuals with $E G F R$-mutant lung cancer (21). In our study, a higher level of $A X L$ expression was observed in the $101 \mathrm{ACs}$ with EGFR mutations compared to that in ACs without EGFR mutations. ACs without $E G F R$ mutations expressed the lowest level of AXL compared to 
those with G719A/S and delE746_A750 mutations. Higher levels of AXL expression were observed in micropapillary ACs compared to those in other subtypes harboring EGFR mutations and in acinar ACs with lymph node invasion. These data suggest that $A X L$ activation may contribute to the invasiveness of acinar and micropapillary ACs together with $E G F R$ activity. The activation of $C R K L$ and $A X L$, together with EGFR mutations, may affect the biological behavior of solid ACs. By contrast, LPAs, which are known to present with mild invasiveness, also exhibited lower CRKL and AXL expression levels, regardless of the EGFR status. Previous studies reported lepidic growth to be associated with a more favorable survival outcome in small solitary resected lung ACs with an invasive component (44-46), suggesting that LPA is relatively indolent among $\mathrm{AC}$ subtypes. As regards the roles of $C R K L$ and $A X L$ in lung ACs according to the EGFR and $A L K$ status, the exact histological types should be considered in order to evaluate the biological behaviors and prognosis of these ACs, since there are significant differences in the expression of CRKL and AXL among various lung AC subtypes.

\section{Acknowledgements}

We would like to thank Xue-Jing Chen, Li Zhang and Chen Zhang for their support in sample collection. This study was supported by the Beijing Foundation for Distinguished Scientists (grant no. 2009D003013000001) awarded by the Beijing Board of Health.

\section{References}

1. Parkin DM, Bray F, Ferlay J and Pisani P: Global cancer statistics, 2002. CA Cancer J Clin 55: 74-108, 2005.

2. Boyle P and Levin B (eds): World Cancer Report 2008. IARC Scientific Publications, Lyon, 2008.

3. Curado MP, Edwards B, Shin HR, Storm H, Ferlay J, Heanue M and Boyle P (eds): Cancer Incidence in Five Continents. Vol IX. IARC Scientific Publications, Lyon, 2007.

4. Terasaki H, Niki T, Matsuno Y, et al: Lung adenocarcinoma with mixed bronchioloalveolar and invasive components: clinicopathological features, subclassification by extent of invasive foci, and immunohistochemical characterization. Am J Surg Pathol 27: 937-951, 2003.

5. Travis WD, Brambilla E, Noguchi M, et al: International Association for the Study of Lung Cancer/American Thoracic Society/European Respiratory Society international multidisciplinary classification of lung adenocarcinoma. J Thorac Oncol 6: 244-285, 2011.

6. Travis WD, Brambilla E, Muller-Hermelink HK and Harris CC (eds): Pathology and Genetics of Tumours of the Lung, Pleura, Thymus and Heart. IARC Press, Lyon, 2004.

7. Travis WD, Colby TV, Corrin B, Shimosato Y and Brambilla E (eds): Histological Typing of Lung and Pleural Tumors. 3rd edition. Springer, Berlin, 1999.

8. Lynch TJ, Bell DW, Sordella R, et al: Activating mutations in the epidermal growth factor receptor underlying responsiveness of non-small-cell lung cancer to gefitinib. New Engl J Med 350: 2129-2139, 2004.

9. Riely GJ, Politi KA, Miller VA and Pao W: Update on epidermal growth factor receptor mutations in non-small cell lung cancer. Clin Cancer Res 12: 7232-7241, 2006.

10. Sakai K, Arao T, Shimoyama T, et al: Dimerization and the signal transduction pathway of a small in-frame deletion in the epidermal growth factor receptor. FASEB J 20: 311-313, 2006.

11. Soda M, Choi YL, Enomoto M, et al: Identification of the transforming EML4-ALK fusion gene in non-small-cell lung cancer. Nature 448: 561-566, 2007.

12. Kwak EL, Bang YJ, Camidge DR, et al: Anaplastic lymphoma kinase inhibition in non-small-cell lung cancer. New Engl $\mathrm{J}$ Med 363: 1693-1703, 2010.
13. Gandhi L and Janne PA: Crizotinib for ALK-rearranged non-small cell lung cancer: a new targeted therapy for a new target. Clin Cancer Res 18: 3737-3742, 2012.

14. Rodig SJ, Mino-Kenudson M, Dacic S, et al: Unique clinicopathologic features characterize ALK-rearranged lung adenocarcinoma in the western population. Clin Cancer Res 15: 5216-5223, 2009.

15. Mino-Kenudson M, Chirieac LR, Law K, et al: A novel, highly sensitive antibody allows for the routine detection of ALK-rearranged lung adenocarcinomas by standard immunohistochemistry. Clin Cancer Res 16: 1561-1571, 2010.

16. ten Hoeve J, Kaartinen V, Fioretos T, et al: Cellular interactions of CRKL and SH2-SH3 adaptor protein. Cancer Res 54: 2563-2567, 1994.

17. Senechal K, Halpern J and Sawyers CL: The CRKL adaptor protein transforms fibroblasts and functions in transformation by the BCR-ABL oncogene. J Biol Chem 271: 23255-23261, 1996.

18. Hafizi S and Dahlback B: Signalling and functional diversity within the Axl subfamily of receptor tyrosine kinases. Cytokine Growth Factor Rev 17: 295-304, 2006.

19. Goruppi S, Ruaro E, Varnum B and Schneider C: Requirement of phosphatidylinositol 3-kinase-dependent pathway and Src for Gas6-Axl mitogenic and survival activities in NIH 3T3 fibroblasts. Mol Cell Biol 17: 4442-4453, 1997.

20. Hector A, Montgomery EA, Karikari C, et al: The Axl receptor tyrosine kinase is an adverse prognostic factor and a therapeutic target in esophageal adenocarcinoma. Cancer Biol Ther 10: 1009-1018, 2010

21. Zhang Z, Lee JC, Lin L, et al: Activation of the AXL kinase causes resistance to EGFR-targeted therapy in lung cancer. Nat Genet 44: 852-860, 2012.

22. Paccez JD, Vasques GJ, Correa RG, et al: The receptor tyrosine kinase Axl is an essential regulator of prostate cancer proliferation and tumor growth and represents a new therapeutic target. Oncogene 32: 689-698, 2013.

23. Cai YR, Zhang HQ, Qu Y, et al: Expression of MET and SOX2 genes in non-small cell lung carcinoma with EGFR mutation. Oncol Rep 26: 877-885, 2011.

24. Lee HJ, Xu X, Choe G, et al: Protein overexpression and gene amplification of epidermal growth factor receptor in nonsmall cell lung carcinomas: Comparison of four commercially available antibodies by immunohistochemistry and fluorescence in situ hybridization study. Lung Cancer 68: 375-382, 2010.

25. Motoi N, Szoke J, Riely GJ, et al: Lung adenocarcinoma: modification of the 2004 WHO mixed subtype to include the major histologic subtype suggests correlations between papillary and micropapillary adenocarcinoma subtypes, EGFR mutations and gene expression analysis. Am J Surg Pathol 32: 810-827, 2008.

26. Sica G, Yoshizawa A, Sima CS, et al: A grading system of lung adenocarcinomas based on histologic pattern is predictive of disease recurrence in stage I tumors. Am J Surg Pathol 34: $1155-1162,2010$.

27. De Oliveira Duarte Achcar R, Nikiforova MN and Yousem SA: Micropapillary lung adenocarcinoma: EGFR, K-ras and BRAF mutational profile. Am J Clin Pathol 131: 694-700, 2009.

28. Kim YH, Ishii G, Goto K, et al: Dominant papillary subtype is a significant predictor of the response to gefitinib in adenocarcinoma of the lung. Clin Cancer Res 10: 7311-7317, 2004.

29. Ding L, Getz G, Wheeler DA, et al: Somatic mutations affect key pathways in lung adenocarcinoma. Nature 455: 1069-1075, 2008.

30. Okudela K, Woo T, Mitsui H, et al: Proposal of an improved histological sub-typing system for lung adenocarcinoma - significant prognostic values for stage I disease. Int J Clin Exp Pathol 3: 348-366, 2010.

31. Amin MB, Tamboli P, Merchant SH, et al: Micropapillary component in lung adenocarcinoma: a distinctive histologic feature with possible prognostic significance. Am J Surg Pathol 26: 358-364, 2002.

32. Tsutsumida $\mathrm{H}$, Nomoto $\mathrm{M}$, Goto $\mathrm{M}$, et al: A micropapillary pattern is predictive of a poor prognosis in lung adenocarcinoma and reduced surfactant apoprotein A expression in the micropapillary pattern is an excellent indicator of a poor prognosis. Mod Pathol 20: 638-647, 2007.

33. Yoshizawa A, Motoi N, Riely GJ, et al: Impact of proposed IASLC/ATS/ERS classification of lung adenocarcinoma: prognostic subgroups and implications for further revision of staging based on analysis of 514 stage I cases. Mod Pathol 24: 653-664, 2011. 
34. Cheung HW, Du J, Boehm JS, et al: Amplification of CRKL induces transformation and epidermal growth factor receptor inhibitor resistance in human non-small cell lung cancers. Cancer Discov 1: 608-625, 2011.

35. Finberg KE, Sequist LV, Joshi VA, et al: Mucinous differentiation correlates with absence of EGFR mutation and presence of KRAS mutation in lung adenocarcinomas with bronchioloalveolar features. J Mol Diagn 9: 320-326, 2007.

36. Suda K, Murakami I, Katayama T, et al: Reciprocal and complementary role of MET amplification and EGFR T790M mutation in acquired resistance to kinase inhibitors in lung cancer. Clin Cancer Res 16: 5489-5498, 2010.

37. Zhang X, Gureasko J, Shen K, Cole PA and Kuriyan J: An allosteric mechanism for activation of the kinase domain of epidermal growth factor receptor. Cell 125: 1137-1149, 2006.

38. Takeuchi K, Choi YL, Togashi Y, et al: KIF5B-ALK, a novel fusion oncokinase identified by an immunohistochemistry-based diagnostic system for ALK-positive lung cancer. Clin Cancer Res 15: 3143-3149, 2009.

39. Boland JM,Erdogan S, Vasmatzis G, et al: Anaplastic lymphoma kinase immunoreactivity correlates with ALK gene rearrangement and transcriptional up-regulation in non-small cell lung carcinomas. Hum Pathol 40: 1152-1158, 2009.

40. Shaw AT, Yeap BY, Mino-Kenudson M, et al: Clinical features and outcome of patients with non-small-cell lung cancer who harbor EML4-ALK. J Clin Oncol 27: 4247-4253, 2009.
41. Takahashi T, Sonobe M, Kobayashi M, et al: Clinicopathologic features of non-small-cell lung cancer with EML4-ALK fusion gene. Ann Surg Oncol 17: 889-897, 2010.

42. O'Bryan JP, Frye RA, Cogswell PC, et al: Axl, a transforming gene isolated from primary human myeloid leukemia cells, encodes a novel receptor tyrosine kinase. Mol Cell Biol 11: 5016-5031, 1991.

43. Neubauer A, O'Bryan JP, Fiebeler A, Schmidt C, Huhn D and Liu ET: Axl, a novel receptor tyrosine kinase isolated from chronic myelogenous leukemia. Semin Hematol 30 (3 Suppl 3): 34, 1993.

44. Lee HY, Han J, Lee KS, et al: Lung adenocarcinoma as a solitary pulmonary nodule: prognostic determinants of CT, PET, and histopathologic findings. Lung Cancer 66: 379-385, 2009.

45. Yokose T, Suzuki K, Nagai K, Nishiwaki Y, Sasaki S and Ochiai A: Favorable and unfavorable morphological prognostic factors in peripheral adenocarcinoma of the lung $3 \mathrm{~cm}$ or less in diameter. Lung Cancer 29: 179-188, 2000.

46. Lin DM, Ma Y, Zheng S, Liu XY, Zou SM and Wei WQ: Prognostic value of bronchioloalveolar carcinoma component in lung adenocarcinoma. Histol Histopathol 21: 627-632, 2006. 